\title{
Development of a Methodology for Microstructural Description
}

\author{
Vanderley de Vasconcelos ${ }^{* a}$, Wander L. Vasconcelos ${ }^{\mathrm{b}}$ \\ ${ }^{a}$ Centro de Desenvolvimento da Tecnologia Nuclear - CDTN/CNEN, \\ C.P. 941, 30.161-970 Belo Horizonte - MG, Brazil \\ ${ }^{\mathrm{b}}$ Universidade Federal de Minas Gerais, Depto. de Engenharia Metalúrgica e de Materiais, \\ Rua Espírito Santo 35, 30.160-030 Belo Horizonte - MG, Brazil
}

Received: August 15, 1998; Revised: March 30, 1999

\begin{abstract}
A systematic methodology for microstructural description can help the task of obtaining the processing $x$ microstructure $x$ properties $x$ performance relationships. There are, however, some difficulties in performing this task, which are related mainly to the following three factors: the complexity of the interactions between microstructural features; difficulties in evaluating geometric parameters of microstructural features; and difficulties in relating these geometric parameters to process variables. To solve some of these problems, it is proposed a methodology that embodies the following features: takes into account the different possible types of approaches for the microstructural description problem; includes concepts and tools of Total Quality Management; is supported on techniques of system analysis; and makes use of computer modeling and simulation and statistical design of experiments tools. The methodology was applied on evaluating some topological parameters during sintering process and its results were compared with available experimental data.
\end{abstract}

Keywords: microstructural description, methodology, simulation

\section{Introduction}

Microstructure plays an important role in determining the properties of any polycrystalline or amorphous material, and therefore in the performance of the products. However, the parameters and processes that control microstructural evolution have not been yet systematically examined. Traditionally, the task of obtaining the processing $x$ microstructure $x$ property $x$ performance relationships has relied upon the engineer's own knowledge and experience. Therefore, prediction and methods used to control experiments and production have been almost totally dependent on the individual judgments ${ }^{1}$.

The main goal of this work is to develop a methodology that helps dealing with the complex tasks related to microstructural description ${ }^{2}$. This methodology is supported on Total Quality and system analysis tools. The first step is a clear identification of the problem and a comprehensive description of the material processing, microstructures, and properties. In order to determine the important variables and to optimize the processes and experiments, the use of statistical design of experiments is proposed by this methodology.

While most analytical models are often oversimplified to reflect real conditions, models sufficiently complex to

avasconv@urano.cdtn.br

bwlv@urano.cdtn.br describe materials' behavior are usually too complicated to be analytically solved. For this reason, the methodology also suggests that traditional experimental methods can be improved through the conduction of digital experiments, $i$. e., computer modeling and simulation.

The developed methodology can be used to solve some typical problems involving microstructural description. These application examples can include, for instance, the study of particle packing, the characterization of porous bed $^{5}$, and the study of microstructural evolution during the sintering process.

\section{Developed Methodology}

Figure 1 shows, schematically, the developed methodology. The analysis of microstructural problems should start with a clear identification of the required approach. After the definition of the problem approach (whether general or specific) it is necessary to check if there is already a standard (or usual) solution for the problem. The development of methodologies for nanostructure visualization and for obtaining microstructure x processing relationships for a certain material under specific processing conditions are examples of general and specific approaches, respectively. 
The methodology recommends that, if there is no standard solution, the researcher should look for one using PDCA/MASP (Methodology for Analysis and Solution of Problems). This methodology is a variation of the PDCA cycle when the objective is to correct the deviations of actual situation from settled marks (Table 1). The Plan step of the PDCA cycle is subdivided into four steps: problem identification, observation, analysis and plan of action. The Action step is subdivided into standardization and conclusion. The use of the proposed methodology generates new standards for solving microstructural problems. This facilitates the solution of future related problems. By this way,

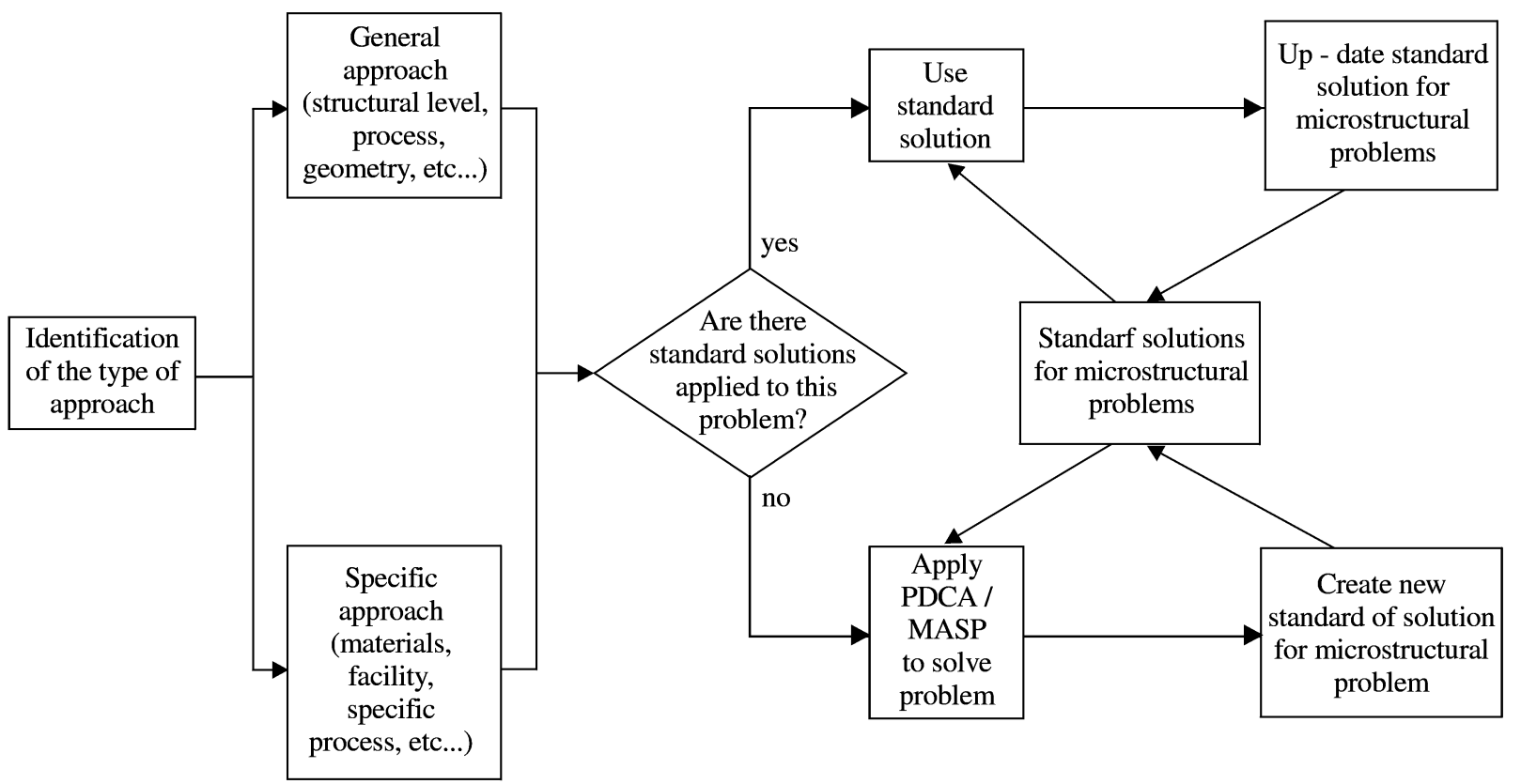

Figure 1. Developed methodology for analysis and solution of microstructural description problems.

Table 1. PDCA/MASP used as part of the methodology for analysis and solution of problems of microstructural description.

\begin{tabular}{|c|c|c|c|}
\hline PDCA & Flow & Step & Objective \\
\hline Plan & 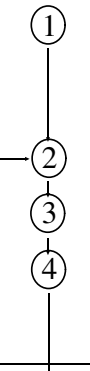 & $\begin{array}{l}\text { Problem statement } \\
\text { Observation } \\
\text { Analysis } \\
\text { Plan of action }\end{array}$ & $\begin{array}{l}\text { Define clearly a problem or process selected for } \\
\text { improvement (materials, approach, structural } \\
\text { levels, marks, etc.). } \\
\text { Observe thoroughly the specific features of the problem. } \\
\text { Search the fundamental causes of the problem. } \\
\text { Elaborate a plan of action to solve the problem (verify } \\
\text { the need of techniques for statistical design of } \\
\text { experiments and elaboration of models). }\end{array}$ \\
\hline Do & (5) & do & Implement elaborated plan of action. \\
\hline Check & & $\begin{array}{c}\text { Check } \\
\text { Were the actions effective? }\end{array}$ & $\begin{array}{l}\text { Check to see whether the implemented plan of action has } \\
\text { solved the problem. }\end{array}$ \\
\hline Action & (8) & $\begin{array}{c}\text { Standardization } \\
\text { Conclusion }\end{array}$ & $\begin{array}{c}\text { Use obtained relationships and develop models and } \\
\text { procedures. } \\
\text { Elucidate obtained thermodynamics and kinetics } \\
\text { relationships, review both the process of model } \\
\text { development and getting the relations, in order to } \\
\text { facilitate future works. Report remaining problems and } \\
\text { successful results. }\end{array}$ \\
\hline
\end{tabular}


the methodology embodies the concept of expert systems: in a continuum enhancement process, new standards are generated, while the existing ones are updated and enhanced $^{3}$.

With the purpose of structuring the methodology, each step shown on Table 1 can be detailed on its tasks and useful tools. Inside the step called problem statement, a general diagram of processing $x$ structure $x$ properties $x$ performance relationships should be elaborated for each analyzed microstructural description problem. It is necessary to define the structural level of interest, which can be engineering, microstructure, nanostructure, atomic or subatomic level. The emphasis in this step should be addressed to details of the required microstructural approach and on identification of materials, methods, and purposes of processing. Under Total Quality viewpoint, a problem is always defined as a difference between actual situation and a desired value called mark. This step should therefore include a clear definition of the mark that the researcher wants to reach.

During the observation step, the researcher should gather data about the conditions under which the problem arises and the state-of-the-art of possible solutions. This is a very important opportunity to have a better understanding of the problem and "let the data speak." This step avoids the common human tendency of looking for solutions only taking into account individual knowledge and judgments. It is necessary to feed the individual knowledge and judgments with the facts and data, looking for solutions on the right direction.

During the analysis step, the fundamental causes of the problem should be identified. This task should start with the identification of: possible microstructural features; most important geometric parameters; and most important process variables. The use of Pareto charts and cause-andeffect diagrams should aid this step ${ }^{2}$.

After the identification of possible causes of the problem it is necessary to elaborate a plan of action to look for the solutions. The actions should be taken over the fundamental causes of the problems and not over their effects. The researcher should analyze the alternatives of solutions, mainly considering their efficiencies and costs. The plan of action, through the use of the tool, known as $5 \mathrm{WlH}^{3}$, should define What actions will be taken, When they will be taken, Who will perform the tasks, Where they will be performed, and Why they will be performed. The plan of action should also contain the procedures needed to implement the actions (How).

Particularly, when there are many possible factors and their influences on the response variables are poorly understood, it is necessary to include statistical experiment design and analysis techniques. Sometimes, when experimental determination of certain parameters is difficult to be performed, implementation of models should be done. The researcher should consider all alternatives of models before deciding which one to adopt during the implementation of the plan of action. The implementation of the plan of action, during Do step, should only be carried out after training of the involved technicians in performing their tasks.

During Check step, the results of the implemented plan of action should be compared with the established marks in order to verify if the plan was effective. Data collected before and after the implementation of plan of action should be checked in order to verify if undesired results still remain. If the founded solution was not successful, the researcher should go back to observation step, gather more data, and repeat all the process.

During Standardization step, the researcher should act on the process, taking into account the obtained results, setting and using standards, so that the reached marks be sustained or improved. The developed relationships, models, and procedures should be reported in order to be used to solve analogue problems.

The obtained relationships, during the Conclusion step, should be elucidated for the matters of thermodynamics and mechanisms. In addition, the researcher should review both the processes of model development and getting the relations in order to facilitate future works. He should also report the remaining problems and the successful results.

During the mentioned steps, the researcher can use many tools in order to: structure the problem-solving process; identify the fundamental causes; avoid bypassing important factors that affect the analyzed effects; and aiding the ranking and selection of options. Examples of useful tools that can be applied in the context of the developed Methodology for Microstructural Description are described as follows:

\subsection{Cause-and-effect diagrams}

They illustrate the relationships between a process (effect) and all possible problems (causes) influencing the process, by sorting out and grouping these problems ${ }^{4}$. They are also called "Ishikawa diagrams" after its inventor, Kaoru Ishikawa, and "fishbone diagrams" because of its appearance. One basic approach to construct such diagram uses the six fundamental components of any process: methods, materials, machine, manpower, measurement and environment. In addition to the documentation, this tool provides structure to the problem-solving effort. This is carried out through the research of why of each cause of the central horizontal line (the fish's spine), which are diagrammed as appendages of the horizontal line. To each one of these main appendages, subsidiary branches, or networks of branches, to delineate potential causes at any desired level of details, can be added. Figure 2 illustrates a cause-and-effect diagram used to find the possible causes that affects the microstruture during a generic processing. 


\subsection{Decision table}

It shows the actions to be taken as consequence of decisions listed in a systematic way ${ }^{5}$. Table 2 shows a simplified decision table to choose the type of model that will be used in the study of any microstructural evolution process. In this table, $Y$ corresponds to Yes (model option shown on each first line of the table), $N$ corresponds to $N o$ (model option shown on each second line of table, in brackets). In this example, the action should be the implementation of a type of model adequate to the analyzed process. The decision table has the advantage of forcing the use of all possibilities $\left(2^{n}\right.$, where $n$ is the number of options). A more detailed analysis should reject impossible combinations of options that can appear in the table.

\section{Computer Modeling and Simulation}

When the chosen strategy to solve the microstructural problem includes a modeling step, the researcher can, in principle, implement the models in any computer environment with high-level languages and graphical resources ${ }^{6}$. However, the complexity of typical computer graphics, solid modeling, and digital image processing routines, would become this task very hard and time and effort consuming. For this reason, the choice of an adequate environment is an important step of this work. The availability of basic routines for graphic manipulations, mainly routines for solid modeling, is a very important feature of such environment.

The chosen environments includes the AutoCAD software package that has the AutoLISP high-level computer language built-in and can also be programmed in $\mathrm{C}^{7}$. This facilitates the implementation of stochastic computer models. The available resources, related to solid modeling, facilitate the creation, edition, and analysis of simulated microstructures. This can be carried out through the use of available primitives and functions.

\section{Statistical Design of Experiments}

In multivariable processes, where the importance of each variable can be determined, the optimization is an useful tool for better understanding of the systems and verifying the effect of each process variable on selected response variables. To do this task it is suggested the use of the optimization methods based on experimental designs, as factorial designs and surface response methodol-

Table 2. Decision table to choose the type of model to be used in the study of any microstructual evolution process ( $Y$ corresponds to Yes; $N$ corresponds to No, options in brackets).

\begin{tabular}{|c|c|c|c|c|c|c|c|c|c|c|c|c|c|c|c|c|}
\hline Type of Model & 1 & 2 & 3 & 4 & 5 & 6 & 7 & 8 & 9 & 10 & 11 & 12 & 13 & 14 & 15 & 16 \\
\hline $\begin{array}{l}\text { steady-state } \\
\text { (kinetic) }\end{array}$ & $\mathrm{Y}$ & $\mathrm{Y}$ & $\mathrm{Y}$ & $\mathrm{Y}$ & $\mathrm{Y}$ & $\mathrm{Y}$ & $\mathrm{Y}$ & $\mathrm{Y}$ & $\mathrm{N}$ & $\mathrm{N}$ & $\mathrm{N}$ & $\mathrm{N}$ & $\mathrm{N}$ & $\mathrm{N}$ & $\mathrm{N}$ & $\mathrm{N}$ \\
\hline $\begin{array}{l}\text { Simulation } \\
\text { (mathematical) }\end{array}$ & $\mathrm{Y}$ & $\mathrm{Y}$ & $\mathrm{Y}$ & $\mathrm{Y}$ & $\mathrm{N}$ & $\mathrm{N}$ & $\mathrm{N}$ & $\mathrm{N}$ & $\mathrm{Y}$ & $\mathrm{Y}$ & $\mathrm{Y}$ & $\mathrm{Y}$ & $\mathrm{N}$ & $\mathrm{N}$ & $\mathrm{N}$ & $\mathrm{N}$ \\
\hline $\begin{array}{l}\text { Discrete } \\
\text { (continuous) }\end{array}$ & $\mathrm{Y}$ & $\mathrm{Y}$ & $\mathrm{N}$ & $\mathrm{N}$ & $\mathrm{Y}$ & $\mathrm{Y}$ & $\mathrm{N}$ & $\mathrm{N}$ & $\mathrm{Y}$ & $\mathrm{Y}$ & $\mathrm{N}$ & $\mathrm{N}$ & $\mathrm{Y}$ & $\mathrm{Y}$ & $\mathrm{N}$ & $\mathrm{N}$ \\
\hline $\begin{array}{l}\text { Deterministic } \\
\text { (probabilistic) }\end{array}$ & $\mathrm{Y}$ & $\mathrm{N}$ & $\mathrm{Y}$ & $\mathrm{N}$ & $\mathrm{Y}$ & $\mathrm{N}$ & Y & $\mathrm{N}$ & $\mathrm{Y}$ & $\mathrm{N}$ & $\mathrm{Y}$ & $\mathrm{N}$ & $\mathrm{Y}$ & $\mathrm{N}$ & $\mathrm{Y}$ & $\mathrm{N}$ \\
\hline
\end{tabular}

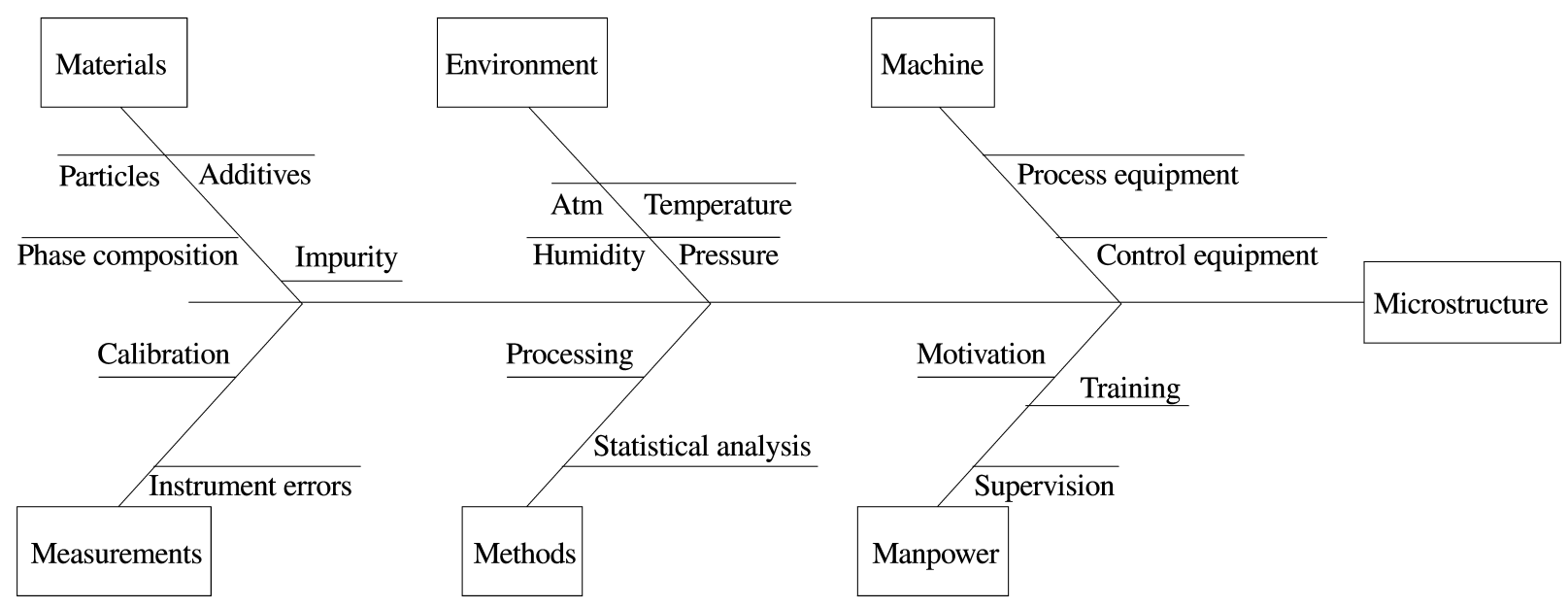

Figure 2. Cause-and-effect diagram used to find the possible causes that affect the microstructure during a generic processing. 
ogy ${ }^{8}$. To apply the surface response methodology, it is necessary, at first, to plan the experiments through the factorial design. Through the use of the results of factorial design, it is possible to compute the main effects of treatments and the interaction effects over response variables. In addition, the researcher can determine the more important effects and adjust empirical linear models relating factors and response variables.

\section{Application of the Methodology}

In order to illustrate the application of the methodology a simple example that uses some of the suggested tools was chosen. The methodology was applied to the problem of determination of topological parameters during the sintering process. The difficulties in determining experimentally the connectivity and coordination number of particles justify the use of computer simulation techniques to solve this problem. The use of a PDCA cycle indicated a plan of action that included the random packing of spherical particles to simulate the green body. The frequency distribution of contacts per particle after sintering of the simulated body (volumetric fraction of pores nearly 0.3 ) is compared with available experimental results related to sintering of spherical particles of copper ${ }^{9}$. As shown on Fig. 3 the simulation results present good agreement with the experimental ones.

\section{Conclusion}

It was developed a structured methodology for microstructural description, taking into account the geometric properties of the microstructure. This methodology can be applied to solve many problems of Materials Science and Engineering, for instance in: selecting microstructural properties that can affect the analyzed processes; obtaining parameters of difficult experimental access; choosing adequate models to specific processes; conducting and optimizing experiments; studying the sintering process. In order to illustrate the use of the methodology it was applied

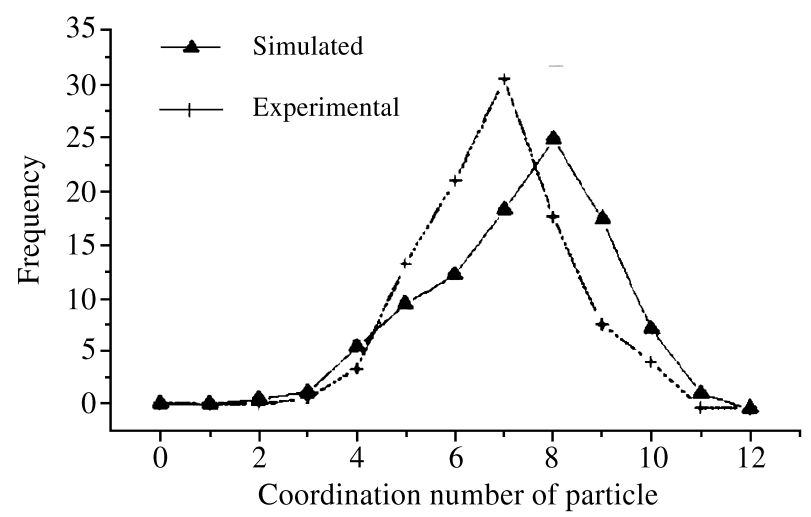

Figure 3. Frequency distribution of coordination number of particles during sintering (volumetric fraction nearly 0.3 ). on evaluating topological parameters during sintering process and its results presented good agreement with available experimental data.

The starting point for the process of troubleshooting and problem-solving should be a systematic approach for the microstructural description, under the point of view of Materials Science and Engineering. It is recommended the use of the Methodology of Analysis and Solution of Problems of Total Quality Management (PDCA/MASP) as a way of planning and structuring the conduction of the experiments, assuring that no step of the problem-solving process is bypassed.

The use of tools like cause-and-effect diagrams and decision tables can be very useful to identify the most important factors and what kind of model should be implemented. The developed methodology also suggests the use of computer modeling and simulation in order to improve and conduct the experiments. The techniques of statistical design of experiments, like factorial design and surface response methodology, shall be used to identify the factors and its interactions that has influenced the selected response variables and to optimize the experiments.

\section{Acknowledgments}

This work was supported by PADCT/FINEP, FAPEMIG and CDTN/CNEN.

\section{References}

1. Kwon, O. A technology for the prediction and control of microstructural changes and mechanical properties in steel. ISIJ International, v. 32, n. 3, p. 350-358, 1992.

2. Vasconcelos, V. Desenvolvimento e aplicação de uma metodologia para a descrição microestutural. Tese de Doutorado, Departamento de Engenharia Metalúrgica, Universidade Federal de Minas Gerais, Belo Horizonte, MG, Brasil, 1997.

3. Campos, V. TQC - Gerenciamento da rotina do trabalho do dia-a-dia. Bloch Editores, Rio de Janeiro, Brasil, 1994.

4. Contino, A.V. Improve plant performance via statistical process control. Chemical Engineering. v. 94, n. 10, p. 95-102, 1987.

5. Gane, C.; Sarson, T. Análise estruturada de sistemas. Livros Técnicos e Científicos, Rio de Janeiro, RJ, Brasil, 1984.

6. Zheng, J.; Johnson, P.F. Computer simulation of particle packing and sintering. Ph.D. Thesis. Alfred University, Alfred, NY, 1991.

7. Head, G.O. AutoCAD 3D - Guia ilustrado do AutoCAD em terceira dimensão. MAKRON Books do Brasil Editora Ltda, SP, Brasil, 1994. 
8. Neto, B.N.; Scarminio, I.S.; Bruns, R.E. Planejamento e otimização de experimentos, Editora da UNICAMP, Campinas, SP, Brasil, 1995.
9. Rhines, F.N.; DeHoff, R.T.; Kronsbein, J. A topological study of the sintering process - Final Report. US Atomic Energy Commission, Gainesville, Florida, 1969. 